\title{
Correction to: Rarefied gas effect in hypersonic shear flows
}

\author{
Jie Chen ${ }^{1} \cdot$ Heng Zhou ${ }^{1}$
}

Published online: 10 June 2021

(c) The Chinese Society of Theoretical and Applied Mechanics and Springer-Verlag GmbH Germany, part of Springer Nature 2021

\section{Correction to: \\ Acta Mechanica Sinica (2021) 37(1):2-17 \\ https://doi.org/10.1007/s10409-021-01051-9}

In the original publication two mistakes caused by typesetting emerged during the Springer internal production. This is a correction for them:

(1) For Eq. (4), one negative sign should be removed in the constitutive relation for stress $\tau$. The superscript of stress $\tau$ is (1). In short, the equation for stress should be $\tau_{x y}^{(1)}=\mu \frac{\partial u}{\partial y}$. The formula for heat flux $q_{y}$ is correct.

(2) For Table 1, the content in the cell of the first row, last column should be changed from "(DSMC)" to " $C_{D}(\mathrm{~N} / \mathrm{m})$ (DSMC)".

Publisher's Note Springer Nature remains neutral with regard to jurisdictional claims in published maps and institutional affiliations.

The original article can be found online at https://doi.org/10.1007/ s10409-021-01051-9.

\footnotetext{
Jie Chen

jie.chen@tju.edu.cn

Heng Zhou

hzhou1@tju.edu.cn

1 Laboratory of High-speed Aerodynamics, Tianjin University,

Tianjin 300072, China
} 